\title{
Characterization of Diarrheagenic Escherichia Coli Serotypes Isolated from Poultry and Humans
}

\author{
Ahmed Byomi ${ }^{1}$, Sherif Zidan ${ }^{1}$, Mohamed Diab ${ }^{2}$, Gopal Reddy ${ }^{3}$, Abiodun Adesiyun ${ }^{4}$ and Woubit \\ Abdela $^{3 *}$ \\ ${ }^{1}$ Department of Animal Hygiene and Zoonoses, Faculty of Veterinary Medicine, University of Sadat City, Egypt \\ ${ }^{2}$ Department of Animal Hygiene and Zoonoses, Faculty of Veterinary Medicine, New Valley Assiut University, Egypt \\ ${ }^{3}$ Department of Pathobiology, College of Veterinary Medicine, Nursing and Allied Health, Tuskegee University, Tuskegee, USA \\ ${ }^{4}$ School of Veterinary Medicine, Faculty of Medical Sciences, University of the West Indies, St. Augustine, Trinidad and Tobago
}

Received: 31 October, 2016; Accepted: 05 January, 2017; Published: 16 January, 2017

*Corresponding author: Woubit Abdela, Department of Pathobiology, College of Veterinary Medicine, Nursing and Allied Health, Tuskegee University, Tuskegee, USA, Office: +1 (334) 727-8278, Fax: +1 (334)-724-4277; E-mail: wabdela@mytu.tuskegee.edu

\begin{abstract}
Virulent strains of Escherichia coli cause colibacillosis, an important disease in poultry which also cause diarrheagenic episodes and deaths in humans. Here we present the prevalence and characteristics of $E$. coli strains isolated from different poultry management systems and in-contact humans. A total of 1,528 samples from broilers (908), ducks (253), backyard chickens (117) and in-contact humans (250) were collected, and isolates from these sources were tested to detect verocytotoxigenic and virulence genes $s t x_{1} s t x_{2}, e a e$, ST and LT. The prevalence of $E$. coli was $43.6 \%$, $57.7 \%, 53.0 \%$ and $7.2 \%$ in broilers, ducks, backyard chickens and humans respectively $\left(\mathrm{P}<0.05 ; \mathrm{X}^{2}\right)$. Frequency ranged from $41.5 \%$ $(78 / 188)$ in unabsorbed yolk sacs to $49.9 \%(188 / 371)$ in septicemic lesions $\left(\mathrm{P}>0.05 ; \mathrm{X}^{2}\right)$. Thirty of the $100 \mathrm{E}$. coli isolates tested were verocytotoxigenic, $31.7 \%(26 / 82)$ and $22.0 \%(4 / 18)$ from poultry and human samples respectively, with respective $20.0 \%, 53.3 \%$, $26.7 \%$, and $46.7 \%$ for stx $_{1}$ stx ${ }_{2}$, stx $x_{1}$ stx $x_{2}$ and eae virulence genes $(\mathrm{P}<$ $\left.0.05 ; \mathrm{X}^{2}\right)$. Serogroups 02 (30.0\%), $0128(16.0 \%), 0125(13.0 \%)$ and $0114(11.0 \%)$ were the predominant isolates in both poultry and human. Poultry species are potential reservoirs of human toxigenic E. coli.
\end{abstract}

Keywords: E. coli; VTEC strains; Serogroups; Virulence genes; Multiplex PCR

\section{Introduction}

Six categories of $E$. coli have been widely associated with diarrhea in several epidemiological studies. These groups include the enteropathogenic E. coli (EPEC), enteroaggregative $E$. coli (EAEC), enterotoxigenic E. coli (ETEC), enteroinvasive $E$. coli (EIEC), and enterohemorrhagic E. coli (EHEC) which are generally regarded as Shiga toxin-producing E. coli (STEC) and diffusely adherent E. coli (DAEC) based on the pathogenic mechanisms [1].

Avian pathogenic E. coli (APEC) strains produce serious extraintestinal lesions in poultry causing high morbidity and mortality in chickens and turkeys, leading to considerable economic losses [2]. In addition, E. coli is a common and an important pathogen that causes at least $5 \%$ of mortalities in poultry flocks [3], including air sacculitis, colisepticemia, synovitis, osteomyelitis and cellulitis [4]. Poultry has also been reported to be a reservoir for extra-intestinal pathogenic E. coli 045:K1:H7-B2-ST95 in humans [5] and the zoonotic potential of APEC strains is under consideration [6].

EPEC infections are associated with outbreaks of neonatal diarrhea in infants from developing countries with clinical presentations that can range from self-limiting diarrhea to chronic enteritis and wasting [1]. Shiga toxins (stx) produced by EHEC strains induce local damage in the colon resulting in hemorrhagic diarrhea, necrosis and intestinal perforation. In addition, stx target the kidneys where they damage the renal endothelial cells and occlude the microvasculature. The resulting nephritis leads to hemolytic uremic syndrome (HUS) which consists of acute renal failure, thrombocytopenia and micro angiopathic hemolytic anemia [1].

Although molecular methods for identifying specific virulence genes are valuable procedures, serotyping remains a useful tool for epidemiologic studies. Globally, numerous studies have been conducted to determine the $E$. coli serotypes most frequently associated with disease in poultry [7]. PCR has been developed to detect specific genes important in the virulence of microorganisms [8]. It has also been reported that the similarity of virulence factors between septicemic E. coli strains in humans and avian pathogens represents a significant zoonotic risk [9]. Studies by others have established similarities in the characteristics (serogroups, virulence genes and antibiograms) of $E$. coli strains isolated from poultry and poultry farm workers $[10,11,12]$.

Therefore, the objectives of this study were to investigate the potential zoonotic spread of $E$. coli serogroups, and to compare the characteristics virulence genes of isolates from poultry and in-contact human beings, in addition the study assessed the usefulness of VCA in the detection of VTEC (vero toxigenic E. coli). 


\section{Methodology}

\section{Sample collection}

A total of 1,528 sampleswere collected from rural communities in Kom Hamada and El-Delengate centers, El-Behera Province, Egypt between May 2012 and April 2013. Overall, a total of 1278 cloacal samples were collected from poultry comprising 908 from broilers, 253 from ducks and 117 from backyard chickens. Litter samples were collected in sampling polyethylene bags, swabs were obtained from cloacae of live broilers or ducks and from septicemic lesions and unabsorbed yolk sac of recently dead birds, were dipped in buffered peptone water (BPW) (Oxoid Ltd., UK) and transported immediately to the laboratory of the Department of Animal Hygiene and Zoonoses, Faculty of Veterinary Medicine, Sadat University, Egypt.

Human stool samples were collected from the health centers and clinical laboratories serving the villages. For the 250 stool samples collected, history on the health status (diarrhea/no diarrhea) and contact with poultry (contact/no contact) was obtained. Overall, the distribution of the humans associated with the different management systems and poultry types are as follows: Broiler farm-related persons, 161; duck farmrelated persons, 59 and backyard chicken associated persons, 30 , comprising $64.4 \%, 23.6 \%$ and $12.0 \%$ respective of the 250 human samples collected. The stool samples were handled the same way as described for poultry samples.

\section{Isolation and Identification of E. coli}

One milliliter (1 ml) of homogenized BPW or $1 \mathrm{~g}$ of sample was transferred to Trypticase soy broth (TSB) and incubated overnight at 37oC. Loopful from incubated TSB was streaked for isolation on MacConkey agar plates and incubated for $24 \mathrm{~h}$ at $37 \mathrm{oC}$. Lactose-fermented colonies were streaked on eosin methylene blue (EMB) agar plates and then incubated for $24 \mathrm{~h}$ at $37 \mathrm{oC}$. The suspected purified colonies with metallic sheen were identified using standard biochemical tests [13].

\section{Selection and Characterization of E. coli Isolates}

One hundred (100) isolates comprising 50,19,13 and 18 E. coli isolates from broiler, ducks, backyards and humans respectively, were randomly selected for further characterization.

\section{Vero Cell Assay (VCA) of E. coli Strains}

The cytotoxicity of the $E$. coli isolates for Vero cells was determined according to the procedure described by Konowalchuk et al. [14].

\section{Serotyping of E. coli Isolates}

Serotyping of $E$. coli isolates was performed in the Serology Unit, Animal Health Research Institute, Doki, Egypt using commercially available antisera (Denka Seiken Co., LTD, Tokyo, Japan) by the slide agglutination test. Detection of stx1, stx2, eae, ST and LT genes in STEC isolates from fecal samples was performed using PCR as described by Paton and Paton [15].

\section{Genomic DNA Extraction}

Pure colonies of bacteria from MacConkey agar plates were sub-cultured into TSB and incubated for $12 \mathrm{~h}$ at $37 \mathrm{oC}$. After incubation, bacteria were collected by centrifugation at 13000 rpm for 2 minutes and the sediment was suspended in equal volume of Tris-EDTA buffer. Thereafter, $100 \mu \mathrm{l}$ of lysozyme solution $(10 \mathrm{mg} / \mathrm{L}), 100 \mu \mathrm{l}$ of proteinase $\mathrm{K}(0.3 \mathrm{mg} / \mathrm{L})$ and $1 \%$ dodecyl sulphate were added. The DNA lysate was extracted once with chloroform/isoamyl alcohol (24:1 ratio by volume), and then extracted with phenol/chloroform/isoamyl alcohol (25: 24: 1 ratio). The aqueous phase was mixed with isopropanol alcohol and stored at $-20 \mathrm{oC}$ for 30 minutes. The precipitated DNA was spooled out, rinsed in $70 \%$ ethanol and dissolves in $0.5 \mathrm{ml}$ of Tris EDTA buffer.

\section{PCR Amplification}

The primers used for PCR amplification are displayed in [Table 1]. PCR was performed in a thermal cycler model (Biometra, Germany). The PCR mix (50 $\mu \mathrm{L}$ ) for each sample consisted the following: $10 \mu \mathrm{L}$ extracted DNA, $5 \mu \mathrm{L}$ primers mix $(0.5 \mu \mathrm{L}$ from every primer), $1 \mu \mathrm{L}$ deoxynucleotide triphosphate (dNTP-mix), $5 \mu \mathrm{L} 10 \mathrm{x}$ buffer, $1 \mu \mathrm{L}$ Taq-DNA polymerase enzyme (5000 U/ $\mathrm{ml}$ ), $28 \mu \mathrm{L}$ ultra-pure deionized water. The reaction mixture was overlaid with mineral oil and incubated in the thermal cycler as follows: The first initial cycle: $940 \mathrm{C}$ for 4 minute (initial denaturation). The subsequent 35 cycles: $940 \mathrm{o}$ for one minute (denaturation), $60 \mathrm{oC}$ for one minute (annealing) and $72 \mathrm{oC}$ for one minute and 30 seconds (extension). The final extension step at $72 \mathrm{oC}$ for 7 minutes then kept at $4 \mathrm{oC}$ as the hold temperature [15]. Expected fragments providing visible bands of appropriate sizes of $180 \mathrm{bp}$ (stx1), $255 \mathrm{bp}$ (stx2), $384 \mathrm{bp}$ (eae), $170 \mathrm{bp}$ (ST) and $322 \mathrm{bp}$ (LT) were considered positive.

\section{Statistical Analyses}

The prevalence of $E$. coli strains, occurrence of virulence markers and serotypes of the isolates from poultry and human sources were compared to detect statistically significant differences using the Chi-square test. The level of significance was set at an alpha 0.05 .

\begin{tabular}{|c|c|c|c|}
\hline $\begin{array}{l}\text { Target } \\
\text { gene }\end{array}$ & Primer sequence & $\begin{array}{c}\text { Amplicon } \\
\text { size }\end{array}$ & Reference \\
\hline Stx & $\begin{array}{c}\text { F: 5'- } \\
\text { ATAAATCGCCATTCGTTGACTAC-3' } \\
\text { R: 5'- AGAACGCCCACTGAGATCATC-3' }\end{array}$ & $180 \mathrm{bp}$ & $\begin{array}{l}\text { Paton and } \\
\text { Paton } \\
(1998)\end{array}$ \\
\hline Stx $x_{2}$ & $\begin{array}{l}\text { F: 5'- GGCACTGTCTGAAACTGCTCC-3' } \\
\text { R: 5'-TCGCCAGTTATCTGACATTCTG-3' }\end{array}$ & $255 \mathrm{bp}$ & $\begin{array}{l}\text { Paton and } \\
\text { Paton } \\
\text { (1998) }\end{array}$ \\
\hline eae & $\begin{array}{l}\text { F: 5'-GACCCGGCACAAGCATAAGC-3' } \\
\text { R: 5'- CCACCTGCAGCAACAAGAGG-3' }\end{array}$ & $384 \mathrm{bp}$ & $\begin{array}{l}\text { Paton and } \\
\text { Paton } \\
\text { (1998) }\end{array}$ \\
\hline St & $\begin{array}{c}\text { F: 5'- } \\
\text { TCTTTCCCCTCTTTTAGTCAGTC-3' } \\
\text { R: 5'-CCAGCACAGGCAGGATTAC-3' }\end{array}$ & $170 \mathrm{bp}$ & $\begin{array}{l}\text { Rappelli et } \\
\text { al. (2001) }\end{array}$ \\
\hline Lt & $\begin{array}{l}\text { F: 5'-TCTATGTGCATACGGAGC-3' } \\
\text { R: 5'-ATACTGATTGCCGCAAT-3 }\end{array}$ & 322 bp & $\begin{array}{l}\text { Rappelli et } \\
\text { al. (2001) }\end{array}$ \\
\hline
\end{tabular}




\section{Results}

\section{Prevalence of E. coli in Poultry and Human contacts}

The prevalence of $E$. coli from three types of poultry and human beings is shown in [Table 2]. Overall, of a total of 1528 samples collected from poultry and human beings, 622 (40.7\%) were positive for E. coli. The prevalence of E. coli was $43.6 \%$, $57.7 \%, 53.0 \%$ and $7.2 \%$ for broiler, ducks, backyard chickens (including litters) and humans respectively and the differences were statistically significant $(\mathrm{P}<0.05 ; \mathrm{X} 2)$. Amongst poultry samples, the prevalence of $E$. coli in broilers (43.6\%) was statistically significantly $(\mathrm{P}<0.05 ; \mathrm{X} 2)$ lower than found in either backyard chickens (53.0\%) or ducks (57.7\%).

Of the 140 humans who had contact with poultry (backyard and/or poultry farms), $13(9.2 \%)$ were positive for E. coli compared with 5 (4.2\%) of 110 humans without poultry contact. The difference was statistically significantly different $(\mathrm{P}<0.05$; $\mathrm{X} 2$ ). The prevalence of $E$. coli in apparently healthy humans (non-diarrheic) and in diarrheic humans was 5.3\% (9 of 171) and $11.4 \%$ (9 of 79 ) respectively. The difference was statistically significantly different $(\mathrm{P}<0.05 ; \mathrm{X} 2)$.

\section{Frequency of Isolation of E. coli by type of Samples Collected}

Overall, E. coli was isolated from $41.5 \%$ (78 of 188), $46.3 \%$ (193 of 417), 49.0\% (148 of 302) and 49.9\% (185 of 371) of unabsorbed yolk sacs, litter, cloacae and septicemic lesions respectively. The differences were however not statistically significant $(\mathrm{P}>0.05 ; \mathrm{X} 2)$. [Figure 1] shows the isolation rates of E. coli from broilers, ducks and backyard chicken samples. For broilers, the range of isolation rates was from 39.1\% (115 of 294) for litter samples to $47.8 \%$ (120 of 251) from for septicemic lesions $(\mathrm{P}<0.05 ; \mathrm{X} 2)$. For duck samples, the lowest frequency of isolation of E. coli was $48.0 \%$ (12 of 25 ) which was originated from unabsorbed yolk sacs while the highest frequency was from litter samples, $65.1 \%$ (54 of 83) again the difference was not statistically significant ( $\mathrm{P}>0.05$; X2). From backyard chickens, the frequency of isolation ranged from $46.7 \%$ (14 of 30) for septicemic lesions to $60.0 \%$ (24 of 40 ) for litter samples but the differences were not statistically significant $(\mathrm{P}>0.05$; X2).

The prevalence of $E$. coli in litters of backyard farms, $60 \%$ (24 of 40 ) and duck farms, $65.1 \%$ (54 of 83 ) were statistically

Table 2: Frequency distribution of $E$. coli isolation in poultry and human samples

\begin{tabular}{|c|c|c|c|}
\hline Source & $\begin{array}{c}\text { Type of poultry and } \\
\text { humans }\end{array}$ & $\begin{array}{c}\text { No. of } \\
\text { samples }\end{array}$ & $\begin{array}{c}\text { No. (\%) positive } \\
\text { for } \text { E. coli }\end{array}$ \\
\hline Poultry & Broiler & 908 & $396(43.6)$ \\
\hline & Duck & 253 & $146(57.7)$ \\
\hline & Back yards chicken & 117 & $62(53.0)$ \\
\hline Human & Sub-total & 1278 & $604(47.3)$ \\
\hline beings & In-contact humans & 250 & $18(7.2)$ \\
\hline & Grand total & 1,528 & $622(40.7)$ \\
\hline
\end{tabular}

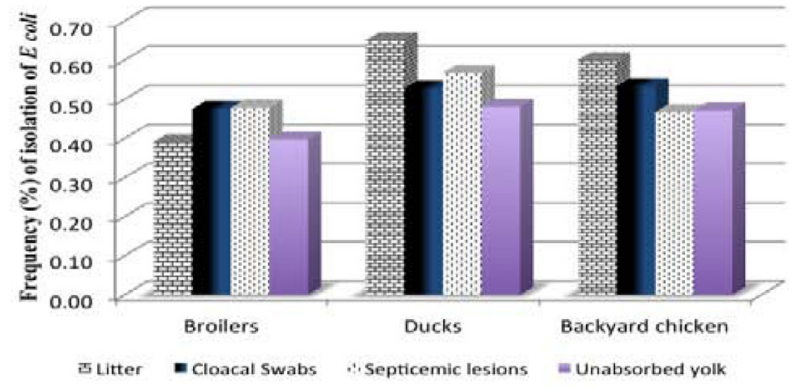

Figure 1: Prevalence of $E$. coli in different types of poultry sampled

significant $(\mathrm{P}<0.05 ; \mathrm{X} 2)$ and higher than detected in litters from broiler farms, 39.1\% (115 of 294).

A comparison of the prevalence of $E$. coli in feces of birds (without inclusion of their litters) revealed a prevalence of $45.8 \%$ (281 of 614 ), $54.1 \%$ (92 of 170 ), and $49.4 \%$ (38 of 77) for broilers, ducks and backyard chickens respectively. The differences however were not statistically significant $(\mathrm{P}>0.05$; $\mathrm{X} 2$ ). For poultry fecal samples, the prevalence of E. coli was $47.7 \%$ (411 of 861) which was ssignificant $(\mathrm{P}<0.05 ; \mathrm{X} 2)$ and highe than the $7.2 \%$ (18 of 250 ) found in humans.

\section{Serogroups of E. coli Isolates}

The predominant serogroups of E. coli isolated were 02 , 0128, 0125, and 0114. Out, of the 100 isolates of E. coli tested, $30(30.0 \%)$ belonged to serogroup 02 which are EPEC strains and of these, $24(80.0 \%)$ and $6(20.0 \%)$ were recovered from poultry and humans respectively [Table 3]. Sixteen (16.0\%) isolates belonged to serogroup 0128 which were ETEC strains and of these $13(81.3 \%)$ were recovered from poultry and 3 $(18.7 \%)$ from humans. Serogroup 0125 was detected in 13 isolates which were ETEC strains and of these 10 (76.9\%) and $3(23.1 \%)$ originated from poultry and humans respectively. Eleven $(11.0 \%)$ isolates belonging serotype 0114 were EPEC strains and of these 9 (81.8\%) were recovered from poultry and $2(18.2 \%)$ from humans.

Of the total 10 different serogroups detected in this study, 10 (100.0\%), 9 (90.0\%), $8(80.0 \%)$ and $8(80.0 \%)$ were found in $E$. coli isolates from broilers, ducks, backyard chickens and humans respectively. Serogroups 019 and 01 found in poultry isolates were not detected in the 18 isolates obtained from the human samples. EPEC strains were most predominant constituting $41.0 \%$ ( 41 of 100), followed by EHEC strains $30.0 \%$ and ETEC strains $29.0 \%$.

\section{Frequency of Detection of Virulence Genes in E. coli Isolates}

The frequency of virulence genes amongst VTEC strains isolated from poultry and human sources as detected by VCA is displayed in [Table 4]. Overall, of the $30 \mathrm{VTEC} / \mathrm{STEC}$ strains from poultry and human isolates, $6(20.0 \%), 16(53.3 \%), 8(26.7 \%)$ and $14(46.7 \%)$ were positive for stx1, stx2, stx1/stx2 and eae respectively. Of the isolates positive for stx genes, stx2 was most 
frequently detected $(57.7 \%)$ in poultry isolates while stx1 was most frequently detected (50.0\%) in human isolates. A similar frequency of eae was detected in poultry and human isolates of $E$. coli, $46.2 \%$ ( 5 of 7 ) and $50.0 \%$ ( 2 of 4 ) respectively.

The frequency of detection of the selected virulence genes in E. coli strains isolated from poultry and human sources by serogroups is shown in [Table 5]. Serogroups 078 and 0111 from poultry sources showed a relatively high frequency of STEC strains, $26.9 \%$ (7 of 26 ) and $23.1 \%$ (6 of 26 ) respectively. The 4 serogroups $(0126,0111,026$ and 078) detected from human isolates of $E$. coli each had a frequency of $25.0 \%$ (1 of 4 ) for STEC strains. [Figure 2] shows the presence of verocytotoxic genes stx1, stx2 and attachment gene eae, from different serotypes 0119, 0126 and 0111 from poultry, and [Figure 3] shows serotypes 0125 and 0128 isolated from human carrying ST and LT genes.

\section{Detection of EAE Genes in EPEC Strains}

Out of the 100 E. coli isolates tested, 41 (41.0\%) were positive for eae genes. The prevalence of EPEC strains (eae gene-positive) in poultry isolates was $40.2 \%$ (33 of 82 ) and $44.4 \%$ (8 of 18) in human isolates. The difference was not statistically significant ( $\mathrm{P}>0.05 ; \mathrm{X} 2$ ). The 2 serogroups (O2 and 0114) tested were

Table 3: Serological characterization of E. coli isolates from poultry and humans

\begin{tabular}{|l|l|l|l|l|l|l|}
\hline \multicolumn{7}{|c|}{ No. of isolates of $\boldsymbol{E}$ coli } \\
\hline Serogroup & Broiler & Duck & Backyard & Human & Total & $\begin{array}{l}\text { Characterization of } \\
\text { strain }\end{array}$ \\
\hline $\mathbf{0 1 1 9}$ & 1 & 1 & 0 & 0 & 2 & EHEC \\
\hline $\mathbf{0 1 2 6}$ & 1 & 1 & 0 & 1 & 3 & EHEC \\
\hline $\mathbf{0 7 8}$ & 4 & 2 & 1 & 1 & 8 & EHEC \\
\hline $\mathbf{0 1 1 1}$ & 4 & 1 & 1 & 1 & 7 & EHEC \\
\hline $\mathbf{0 2}$ & 15 & 6 & 3 & 6 & 30 & EPEC \\
\hline $\mathbf{0 2 6}$ & 3 & 0 & 1 & 1 & 5 & EHEC \\
\hline $\mathbf{0 1}$ & 3 & 1 & 1 & 0 & 5 & EHEC \\
\hline $\mathbf{0 1 2 8}$ & 8 & 3 & 2 & 3 & 16 & ETEC \\
\hline $\mathbf{0 1 1 4}$ & 5 & 2 & 2 & 2 & 11 & EPEC \\
\hline $\mathbf{0 1 2 5}$ & 6 & 2 & 2 & 3 & 13 & ETEC \\
\hline Total & 50 & 19 & 13 & 18 & 100 & -- \\
\hline & & & & & & \\
\hline
\end{tabular}

Table 4: Frequency of virulence genes amongst VTEC strains detected by VCA

\begin{tabular}{|c|c|c|c|c|c|}
\hline \multirow[b]{2}{*}{$\begin{array}{l}\text { Source of } \\
\text { samples }\end{array}$} & \multirow[b]{2}{*}{$\begin{array}{l}\text { No. of VTEC* } \\
\text { isolates }\end{array}$} & \multicolumn{4}{|c|}{ No. (\%) of isolates positive for: } \\
\hline & & $s t x_{1}$ & $s t x_{2}$ & $\begin{array}{l}\text { stx }_{1} \& \\
\text { stx }_{2}\end{array}$ & eae \\
\hline Poultry & 26 & $\begin{array}{l}4 \\
(15.5)\end{array}$ & $\begin{array}{l}15 \\
(57.7)\end{array}$ & $7(26.9)$ & $12(46.2)$ \\
\hline Human & 4 & $\begin{array}{l}2 \\
(50.0)\end{array}$ & $1(25.0)$ & $1(25.0)$ & $2(50.0)$ \\
\hline Total & 30 & $\begin{array}{l}6 \\
(20.0)\end{array}$ & $\begin{array}{l}16 \\
(53.3)\end{array}$ & 8 (26.7) & 14 (46.6) \\
\hline
\end{tabular}

*VTEC: Verocytotoxigenic E. coli

\begin{tabular}{|c|c|c|c|c|c|c|}
\hline \multirow[b]{3}{*}{$\begin{array}{l}\text { Source } \\
\text { of } \\
\text { samples }\end{array}$} & \multirow[b]{3}{*}{ Serogroup } & \multirow[b]{3}{*}{$\begin{array}{l}\text { No. of } \\
\text { E. coli } \\
\text { isolates }\end{array}$} & \multirow{2}{*}{\multicolumn{4}{|c|}{ No. (\%) of isolates positive: }} \\
\hline & & & & & & \\
\hline & & & $s t x_{1}$ & $s t x_{2}$ & $\begin{array}{l}s t x_{1} \& \\
\operatorname{stx}_{2}\end{array}$ & eae \\
\hline \multirow[t]{7}{*}{ Poultry } & 0119 & 2 & $0(0.0)$ & $2(100.0)$ & $0(0.0)$ & $0(0.0)$ \\
\hline & 0126 & 2 & $1(50.0)$ & $1(50.0)$ & $0(0.0)$ & $1(50.0)$ \\
\hline & 0111 & 6 & $1(16.7)$ & $3(50.0)$ & $2(33.3)$ & $4(66.7)$ \\
\hline & 078 & 7 & $1(14.3)$ & $4(57.1)$ & $2(28.6)$ & $5(71.4)$ \\
\hline & 026 & 4 & $1(25.0)$ & $2(50.0)$ & $1(25.0)$ & $0(0.0)$ \\
\hline & 01 & 5 & $0(0.0)$ & $3(60.0)$ & $2(40.0)$ & $2(40.0)$ \\
\hline & Sub-total & 26 & $4(15.4)$ & $15(57.7)$ & 7 (26.9) & $12(46.2)$ \\
\hline \multirow[t]{6}{*}{ Human } & 0126 & 1 & $\begin{array}{l}1 \\
(100.0)\end{array}$ & $0(0.0)$ & $0(0.0)$ & $1(100.0)$ \\
\hline & 0111 & 1 & $0(0.0)$ & $0(0.0)$ & $1(100.0)$ & $0(0.0)$ \\
\hline & 026 & 1 & $0(0.0)$ & $1(100.0)$ & $0(0.0)$ & $0(0.0)$ \\
\hline & 078 & 1 & $\begin{array}{l}1 \\
(100.0)\end{array}$ & $0(0.0)$ & $0(0.0)$ & $1(100.0)$ \\
\hline & Sub-total & 4 & $2(50.0)$ & $1(25.0)$ & $1(25.0)$ & $2(50.0)$ \\
\hline & Grand-Total & 30 & $6(20.0)$ & $16(53.3)$ & 8 (26.7) & $14(46.7)$ \\
\hline
\end{tabular}

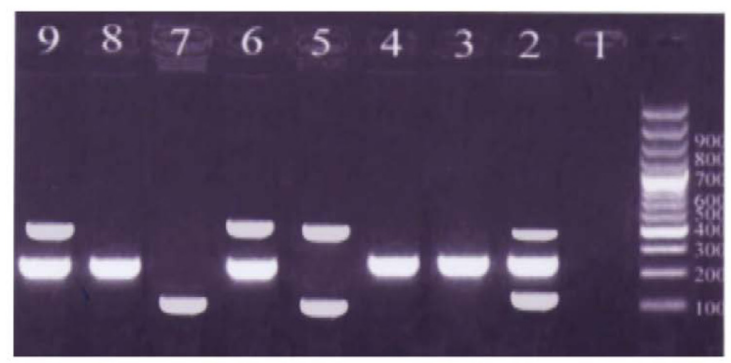

Figure 2: This figure shows the shiga toxin Stx 1 and 2 (180bp, 225bp) and attachment eae (384bp) genes; Lane (M): MW marker $=100 \mathrm{bp}$ DNA ladder (Promega). Lane 1: negative control. Lane 2: positive control $(E$. coli 0157 H7 provided by Animal Health research Institute, Egypt, (Stx1, Stx2 and eae genes)) Lane 3, 4 (Stx2): E. coli 0119 from poultry. Lane 6 (Stx2, eae), 7 (Stx1) E. coli 0126 from poultry, and Lane 5 (eae, Stx1), 8 (Stx2), 9 (eae, Stx2): E. coli 0111 isolates from poultry

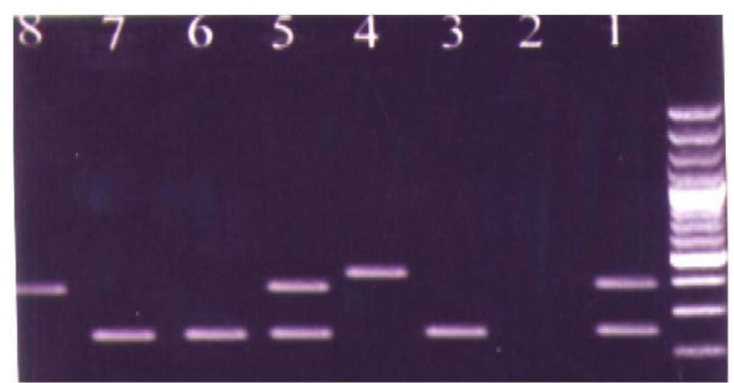

Figure 3: Lane (M): MW marker = $100 \mathrm{bp}$ DNA ladder (Promega). Lane 1: positive control E. coli 0125 containing ST and LT genes of sizes 170 and 324bp respectively. Lane 2: negative control, Lanes 3 (ST), 4 (LT), 5 (ST and LT) are E. coli 0125 isolates from human; Lane 6 (ST), 7 (St), 8 (Lt) are E. coli 0128 isolates from humans 
positive for eae genes. Of a total of 30 EPEC strains that belonged to serogroup 02, $24(80.0 \%)$ and $6(20.0 \%)$ were originated from poultry and humans respectively. For the 11 EPEC strains in serogroup $0114,9(81.8 \%)$ were poultry isolates while $2(18.2$ $\%)$ were recovered from humans.

\section{Frequency of detection of ETEC strains}

29 of the $100 \mathrm{E}$. coli isolates of tested (29.0\%) were ETEC strains, comprising $23(28.0 \%)$ of the 82 poultry isolates and $6(33.3 \%)$ of the 18 human isolates [Table 6]. The difference was not statistically significant $(\mathrm{P}>0.05 ; \mathrm{X} 2)$. ETEC strains were detected in 2 serogroups, 0128 and 0125 human isolates. Occurrence of LT gene was most common in poultry isolates $(43.5 \%)$ but ST gene $(50.0 \%)$ in human isolates of $E$. coli $(\mathrm{P}>$ $0.05 ; \mathrm{X} 2$ ).

\section{Discussion}

The study was conducted using the 'One Health' concept which encompasses the interaction of animals, humans and the environmentin the transmission of diseases [16]. The primary goal was to study the similarities in the prevalence and characteristics of toxigenic E. coli strains in rural communities in Egypt where there is a high animal-human-environment interaction. This is primarily due to the fact that backyard chickens are in very close contact with humans in the households, the exposure of poultry farm workers to E.coli from broilers and ducks and finally, the consumption of poultry products from these villages. These exposures have been reported by other researchers and it is well established that chickens could serve as reservoirs of toxigenic E. coli as a result of poor hygienic practices in rural communities which may pose food safety concerns $[6,11,17]$.

The carriage rate of $E$. coli in feces of poultry which ranged from $45.8 \%$ to $54.1 \%$ in the current study is lower than the 75.5 $\%$ reported for apparently healthy layers and their environments in India [18] and the 78\% reported in ducks by Adzitey et al. [19]. Considerably lower prevalence of $39.4 \%$ was however detected in broilers feces by Abhilasha and Gupta [20]. The isolation of $E$. coli, a normal flora of the intestinal tracks of animals and humans [21], is an indication that poultry could be potential sources of

Table 6: Occurrence of selected virulence genes (ST and LT) in ETEC strains from poultry and human samples

\begin{tabular}{|c|c|c|c|c|c|}
\hline $\begin{array}{c}\text { Source of } \\
\text { isolates }\end{array}$ & Serogroup & $\begin{array}{c}\text { No. of ETEC } \\
\text { isolates }\end{array}$ & ST & LT & ST \& LT \\
\hline Poultry & 0128 & 13 & $3(23.1)$ & $6(46.2)$ & $4(30.8)$ \\
\hline & 0125 & 10 & $4(40.0)$ & $4(40.0)$ & $2(20.0)$ \\
\hline & Sub-total & 23 & $7(30.4)$ & $10(43.5)$ & $6(26.1)$ \\
\hline Human & 0128 & 3 & $2(66.7)$ & $1(33.3)$ & $0(0.0)$ \\
\hline & 0125 & 3 & $1(33.3)$ & $1(33.3)$ & $1(33.3)$ \\
\hline & Sub-total & 6 & $3(50.0)$ & $2(33.3)$ & $1(16.7)$ \\
\hline & Grand-total & 29 & $\begin{array}{c}10 \\
(34.5)\end{array}$ & $12(41.4)$ & $7(24.1)$ \\
\hline
\end{tabular}

*ETEC: Enterotoxigenic $E$. coli the microorganism to contaminate the environment and humans due to poultry meat consumption. Poultry have been recognized as reservoirs of pathogenic organisms such as Salmonella spp., Campylobacter spp., E. coli, amongst others [22].

In our study, although the prevalence of $E$. coli in the poultry species was significantly higher than found in human feces tested, frequencies of isolation of E. coli was reported to vary across countries, $60.0 \%$ [23] and $62.5 \%$ in Bangladesh [24]. On the other hand, the frequency of isolation or detection of $E$. coli by various methods ranged from $0.4 \%$ to $22 \%$ in stool samples from human clinical laboratories in 10 European countries [25].

The prevalence of $E$. coli in humans in contact with poultry (9.2\%) was significantly higher than found in those without poultry contact ( $4.2 \%$ ), showing important zoonotic implications. A much higher frequency $(73.0 \%)$ of isolation of $E$. coli was detected in 30 healthy animal farm workers elsewhere [26]. Several studies have reported the similarity of isolates of $E$. coli regarding the genes and antibiotic sensitivity, recovered from poultry and their human contacts $[10,12]$. Riccobono et al. [11] had however suggested that cross-transmission between children and home raised chickens could not represent a major spreading mechanism for resistant $E$. coli in households of resource-limited settings with high human-animal interaction. It was also of zoonotic significance to have detected the four serogroups of $E$. coli $(0126,0111,026$ and 078) isolated from humans were also recovered from poultry sources in the current study. It would however be necessary to apply more robust genetic tools, such as the pulse-field gel electrophoresis (PFGE) [27], to confirm the relatedness of the isolates. It is however pertinent to mention that the serogroups detected in the current study have also been isolated from poultry and humans elsewhere [28].

The detection of E. coli (39.1\% to $60.0 \%$ ) in the litters of poultry farms (broilers and ducks) and backyard chicken environments is considered high and the organism has been recovered in the litters of poultry houses by others [29]. The significantly lower prevalence of $E$. coli in the litters on broiler farms compared with those from duck farms and backyard chicken environment may reflect a difference in management systems in which human contact is more prevalent on the duck farms and backyard chicken environment than the broiler farms. When changes of litters were completed on the duck farms and backyard chicken environment a higher exposure by humans to fecal matter resulted in a higher prevalence of E. coli, suggesting a higher risk factor for human infections by toxigenic E. coli [12].

The fact that $E$. coli was isolated at a significantly higher frequency from diarrheic humans (14.2\%) than from nondiarrheic (5.3\%) humans may be an indication that the microorganism was responsible either alone or in combination with other pathogens for the episodes. The pathogenic and toxigenic strains of $E$ coli are an established human pathogens $[2-4,30]$.

From epidemiologic, virulence and pathogenic point, out of the 100 isolates tested, 30 (30\%) were confirmed by PCA as VTEC strains and all possessed stx1, stx2 and stx1/stx2 genes 
making them all STEC strains. Other researchers have reported the detection of VTEC from animal sources, for example, in Côte d'Ivoire only one isolate of E.coli was determined to be a STEC strain [31] while Amézquita-Lópe et al. [32] reported isolating STEC strains from cattle, chickens and sheep. However, isolates of $E$. coli from chickens have been reported to be negative for STEC strains in Greece [33] and the USA [34]. Although it has been established elsewhere that STEC strains are responsible for hemorrhagic gastroenteritis [35] in humans, only 4\% of the isolates from humans were STEC strains. This was, higher than the $0.4 \%$ prevalence Shiga toxin strains in diarrheic humans reported by others [[33], however only oone isolate was reported as 0157:HNM positive from human diarrheal stool specimens in Côte d'Ivoire [31]. In our study, a comparatively high prevalence (26\%) of STEC was detected in poultry and their litters, which was considerably higher than the $6 \%$ reported for chickens in Burkina Faso [36].

This is the first documentation of STEC strains from poultry sources in Egypt, an indication that poultry could be important reservoirs of STEC strains for human infections [36, 37].

Overall in our study, VCA detected $30 \%$ of the isolates tested to be VTEC strains, at a frequency of $31.7 \%$ and 22.2 $\%$ in chicken and human isolates respectively. Comparatively lower frequencies of VTEC strains have been documented by others, 11\% [3] and 9.1\% [39] from chickens. The frequency of verocytotoxin producers amongst isolates from Egyptian villages in the current study (22\%) is considerably lower than the $96.6 \%$ reported by Ananias and Yano [38], also using VCA.

The strategy employed in the current research, which used VCA followed by multiplex PCR successfully confirmed the presence of verotoxin (stx1, stx2, stx1/stx2) STEC strains as VTEC strains. Although the sensitivity of Vero cells to stx was first reported by Konowalchuk et al. [14], the cytotoxicity for this cell line remains the "gold standard" for confirmation of putative stx-producing isolates [15]. In our study, there was a $100 \%$ correlation between VCA and multiplex PCR results. However, the only inference that can be made on VTEC-positive (by VCA) and verotoxin gene-positive to classify them as STEC strains because they were not serotyped specifically for 0157 strains, which is a limitation of the current study. It is known that both 0157 and non-0157 STEC strains exist that are VTEC [32].

Our finding that $26.7 \%$ of the 30 STEC isolates were positive for both stx1 and stx2 genes is in agreement with published studies $[43,44]$. The frequencies of detection have also been variable according to reports, with lower frequency of $10 \%$ for stx 1 and $16.5 \%$ for stx 2 genes [45] and a higher frequency than found in our study by others [46]. In our study, a total of 6 (20\%) isolates were positive for only stx1 gene and 16 (53.3\%) for only stx2 gene, a slight variance from the reports of others [39] who stated that stx1 was more frequently detected in STEC strains isolated from human patients with diarrhea.

The detection of $50 \%$ human isolates tested positive for the eae genes, which are usually associated with EPEC strains and known to be responsible for gastroenteritis [40], indicates possible pathogenic significance.

It is also pertinent to mention that $46.2 \%$ of the isolates from poultry from Egyptian villages were positive for EPEC strains and therefore could serve as potential sources for human infections. This by far is higher than reported elsewhere, $37 \%$ in chickens in Burkina Faso [35], 30.0\% in diseased chickens in the USA [7] and 9.52\% from chickens in India [43]. Four serogroups (0126, 0111, 078 and 01 ) of $E$. coli from poultry were eae genes positive and therefore EPEC strains. These strains have been isolated from poultry by others [41].

The prevalence of $8 \%$ for EPEC strains detected in humans in our study compares favorably with the $7.6 \%$ reported for Melbourne infants [42] and $5.9 \%$ found in Berlin infants [42]. However, relatively lower prevalence of $4.57 \%$ for EPEC strains was reported in humans in while considerably higher prevalence has been reported in diarrheic (36.8\%) and non-diarrheic (29.8\%) humans by Garcia and others [44].

ETEC strains producing LT and ST have long been known to be responsible for diarrhea in both humans and animals $[23,25]$. The prevalence of $28 \%$ for ETEC strains in chicken isolates in our study is higher than the $5 \%$ reported for chicken isolates in Burkina Faso [36] but comparative to the $22.8 \%$ and $38.71 \%$ detected in broilers and layers respectively in Bangladesh [23].

Regarding the frequency of detection of ETEC strains from human isolates in our study, $33 \%$ is considerably higher than a range of $0.1 \%$ to $4.2 \%$ reported from human diarrheic patients in ten European countries [25]. This is not a surprise because it has been reported that EPEC strains and other pathogenic and toxigenic strains of $E$. coli are more prevalent in developing countries where poor hygienic practices are more prevalent than in developed countries [25, 45]. Serogroups 0128 and 0125 detected in chicken and human isolates in this study were also reported among ETEC strains [46]. The serotypes and the frequency of detection of both LT and ST genes, albeit at different frequencies, in $E$. coli isolates recovered from chickens and humans in rural communities in Egypt; indicate that they might play an important role as a cause of diarrhea in those areas.

\section{Conclusion}

Poultry (broilers, chickens and ducks) sampled from rural communities in Egypt displayed a significantly higher prevalence of $E$. coli than humans sampled in the same villages. However, the similarities detected amongst the strains of $E$. coli from poultry and human sources regarding the serogroups, EHEC, VTEC, ETEC and EPEC indicate that poultry in these villages have the potential to serve as important reservoirs of infection for humans. It is however imperative to use molecular methods such as the PFGE or MLST for future studies of this nature. This confirms the genetic relatedness of the E. coli strains isolated for poultry and humans in the Egyptian communities studied, which is considered a limitation of this study. It is also noted that although the sample size of 100 used in the current study which was primarily due limited resources, the study design which applied several serological and genetic methods successfully established 
significant similarities in occurrence and characteristics between human and poultry isolates studied. Finally, to the best of our knowledge the present study is the first report that studied the relationship of poultry-human transfer of diarrhegenic E. coli in rural communities in Egypt.

It is recommended that future studies should consider the use of PFGE and/or MLST to definitely confirm the relatedness of $E$. coli isolates from both poultry and human isolates in rural Egyptian communities.

\section{Acknowledgements}

This research is partly funded by the USDA/AFRI/CBG GL 2012-36-22650058. The authors are grateful to colleagues and technical staff at the Department of Animal Hygiene and Zoonosis, Faculty of Veterinary Medicine, University of Sadat City, Egypt and the Department of Animal Hygiene and Zoonosis, Faculty of Veterinary Medicine. New Valley Assiut University of Egypt where isolation and characterization of $E$. coli isolates were conducted. The authors also wish to thank members of the Department of Pathobiology at the Tuskegee University School of Veterinary Medicine for their input in assessing and analyzing the data and finally in preparing the manuscript.

\section{Ethical Approval}

All procedures performed in this study including collection of humal fecal samples and animals were in accordance with the Egyptian ethical standards of the national research committee. All human subject gave their consent for the collection of the fecal samples, with the agreement that any identifying details of the individuals should not be published.

\section{Reference}

1. Kaper JB, Nataro JP, Mobley HLT. Pathogenic E. coli. Nat. Rev. Microbiol. 2004;2(2):123-40.

2. Ashraf, A. Abd El Tawab, Ahmed, A. A. Maarouf, Samir, A. Abd El Al, et al. Detection of some virulence genes of avian pathogenic E. coli by polymerase chain reaction. Benha Veterinary medical Journal. 2014;26(2):159-176.

3. Fantinatti F, Silveira WD, Castro AFP. Characteristics associated with pathogenicity of avian septicaemic Escherichia coli strains. Vet. Microbiol. 1994;41(1-2):75-86.

4. Gross WG. Diseases Due to Escherichia coli in Poultry. CAB International, Wallingford 1994;237-259.

5. Mora A, Viso S, López C, Alonso MP, García-Garrote F, Dabhi G, et al Poultry as reservoir for extra-intestinal pathogenic Escherichia coli 045:K1:H7-B2-ST95 in humans. Vet. Microbiol. 2013;167(3-4):506612. doi: 10.1016/j.vetmic.2013.08.007.

6. Ewers C, Janssen T, Wieler LH. Avian pathogenic Escherichia coli (APEC). Berl Munch Tierarztl Wochenschr. 2003;116(9-10):381-95.

7. Rosario CC, Lopez AC, Tellez IG, Navarro OA, Anderson RC, Eslava CC. Serotyping, virulence genes detection in Escherichia coli isolated from fertile and infertile egg, dead in shell embryos and chickens with yolk sac infection. Avian Dis 2004;48(4):791-802.

8. La Ragione RM, McLaren IM, Foster G, Cooley WA, Woodward MJ Phenotypic and genotypic characterization of avian Escherichia coli 086:K61 isolates possessing a gamma-like intimin. Appl. Environ.
Microbiol. 2002;68(10):4932-4942.

9. Ron EZ. Host specificity of septicemic Escherichia coli: human and avian pathogens. Curr Opin Microbiol 2006;9(1):28-32.

10. Agabou A, Lezzar N, Ouchenane Z, Khemissi S, Satta D, Sotto A, et al. Clonal relationship between human and avian ciprofloxacinresistant Escherichia coli isolates in North-Eastern Algeria. Eur. J. Clin. Microbiol. Infect. Dis. 2015.

11. Riccobono E, Pallecchi L, Mantella A, Bartalesi F, Zeballos IC, Trigoso C, et al. Carriage of antibiotic-resistant Escherichia coli among healthy children and home-raised chickens: a household study in a resourcelimited setting. Microb. Drug Resist. 2012;18(1):83-87. doi: 10.1089/ mdr.2011.0003.

12. Tozzi AE, Niccolini A, Caprioli A, Luzzi I, Montini G, Zacchello G, et al. A community outbreak of haemolytic-uraemic syndrome in children occurring in a large area of northern Italy over a period of several months. Epidemiol. Infect. 1994;113(2):209-219.

13. Quinn P, Markey B, Carter M, Donelly W and Leonard F. Veterinary Microbiology and Microbial disease. West Susse, UK: Blackwell Science Ltd; 2011.

14. Konowalchuk J, Speirs JI, Stavric S. Vero response to a cytotoxin of E. coli. Infect Immun. 1977;18(3):775-779.

15. Paton JC, Paton AW. Pathogenesis and diagnosis of Shiga toxinproducing Escherichia coli infections. Clin Microbiol Rev. 1998;11(3):450-479.

16. Lerner H, Berg C. The concept of health in One Health and some practical implications for research and education: what is One Health? Infect. Ecol. Epidemiol. 2015; 5. doi: 10.3402/iee.v5.25300.

17. Jiang Q, Zhou J, Jiang Z, Xu B. Identifying risk factors of avian infectious diseases at household level in Poyang Lake region, China. Prev Vet Med. 2014;116 (1-2):151-160. doi: 10.1016/j.prevetmed.2014.04.016.

18. Samanta I, Joardar SN, Das PK, Das P, Sar TK, Dutta TK, et al. Virulence repertoire, characterization, and antibiotic resistance pattern analysis of Escherichia coli isolated from backyard layers and their environment in India. Avian Dis. 2014;58(1):39-45.

19. Adzitey F, Liew CY, Aronal AP, Huda N. Isolation of Escherichia coli from Ducks and Duck Related Samples. Asian Journal of Animal and Veterinary Advances 2012;7(4)351-355. DOI: 10.3923/ ajava.2012.351.355

20. Abhilasha SP and Gupta RS. Pathogenicity and in vitro drug resistance of Escherichia coli isolated from colibacillosis cases in chicks of Tarai Region. Ind. J. of Comp. Micrbiol. Immunol. Infect. Dis 2001;22(2):166167.

21. Leimbach A, Hacker J, Dobrindt U. E. coli as an all-rounder: the thin line between commensalism and pathogenicity. Curr Top Microbiol. Immunol. 2013;358:3-32. doi: 10.1007/82_2012_303.

22. Bodhidatta L, Srijan A, Serichantalergs O, Bangtrakulnonth A, Wongstitwilairung B, McDaniel $\mathrm{P}$, et al. Bacterial pathogens isolated from raw meat and poultry compared with pathogens isolated from children in the same area of rural Thailand. Southeast Asian J Trop Med Public Health. 2013;44(2):259-272.

23. Hossain MT, Siddique MP, Hossain FMA, Zinnah MA, Hossain MM, Alam MK, et al. Isolation, Identification, Toxin profile and Antibiogram of Escherichia coli isolated from broilers and layers in Mymensingh district of Bangaladish Bangl. J. Vet. Med. 2008;6 (1):01-05.

24. Nazir KHMNH. Molecular base of diversified Escherichia coli isolates potentiating antibiotic resistant pattern and compromising 
epidemiology. MS Thesis submitted to the Department of Microbiology and Hygiene, Bangladesh Agricultural University, Mymensingh. 2004;

25. Spina A, Kerr KG, Cormican M, Barbut F, Eigentler A, Zerva L, et al. Spectrum of enteropathogens detected by the FilmArray GI Pane in a multicentre study of community-acquired gastroenteritis Clin. Microbiol. Infect 2015;21(8):719-728. doi: 10.1016/j. cmi.2015.04.007.

26. Boonyasiri A, Tangkoskul T, Seenama C, Saiyarin J, Tiengrim S, Thamlikitkul V. Prevalence of antibiotic resistant bacteria in healthy adults, foods, food animals, and the environment in selected areas in Thailand. Pathog. Glob. Health. 2014;108(5):235-245. doi: 10.1179/2047773214Y.0000000148.

27. Solà-Ginés M, Cameron-Veas K, Badiola I, Dolz R, Majó N, Dahbi G, et al. Diversity of Multi-Drug Resistant Avian Pathogenic Escherichia coli (APEC) Causing Outbreaks of Colibacillosis in Broilers during 2012 in Spain. PLoS One. 2015;10(11):e0143191. doi: 10.1371/journal. pone.0143191

28. Blanco JE, Blanco M, Mora A, Jansen WH, García V, Vázquez ML, et al. Serotypes of Escherichia coli isolated from septicaemic chickens in Galicia (northwest Spain). Vet Microbiol. 1998;61(3):229-235

29. Chinivasagam HN, Redding M, Runge G, Blackall PJ. Presence and incidence of food-borne pathogens in Australian chicken litter. $\mathrm{Br}$ Poult Sci. 2010;51(3):311-318. doi: 10.1080/00071668.2010.499424.

30. Kaper JB, Nataro JP, Mobley HL. Pathogenic E. coli. Nat Rev Microbiol. 2004;2 (2):123-140. doi: 10.1038/nrmicro818.

31.Dadié A, Karou T, Adom N, Kétté A, Dosso M. Isolation of enteric pathogeic agents in Côte d'Ivoire: Escherichia coli 0157:H7 and enteroaggregative E. coli. Bull Soc Pathol Exot. 2000;93(2):95-96.

32. Amézquita-López BA, Quiñones B, Soto-Beltrán M, Lee BG, Yambao JC, Lugo-Melchor OY, et al. Antimicrobial resistance profiles of Shiga toxin-producing Escherichia coli 0157 and Non-0157 recovered from domestic farm animals in rural communities in Northwestern Mexico. Antimicrob Resist Infect Control. 2016;5:1. doi: 10.1186/s13756-0150100-5.

33. Pinaka O, Pournaras S, Mouchtouri V, Plakokefalos E, Katsiaflaka A, Kolokythopoulou F, et al. Shiga toxin-producing Escherichia coli in Central Greece: prevalence and virulence genes of 0157:H7 and non-0157 in animal feces, vegetables, and humans. Eur J Clin Microbiol Infect Dis. 2013;32(11):1401-1408. doi: 10.1007/s10096013-1889-6.

34. Ferens WA, Hovde CJ. Escherichia coli 0157:H7: animal reservoir and sources of human infection. Foodborne Pathog. Dis. 2011;8(4):465487. doi: 10.1089/fpd.2010.0673.

35. Pachkoria E, Vashakidze E, Megrelishvili T, Tevzadze L. Clinical and epidemiological peculiarities of hemorrhagic colitis complicated by hemolytic-uremic syndrome. Georgian Med News 2014;234:70-73.

36. Kagambèga A, Martikainen O, Siitonen A, Traoré AS, Barro N, Haukka K. Prevalence of diarrheagenic Escherichia coli virulence genes in the feces of slaughtered cattle, chickens, and pigs in Burkina Faso. Microbiol open. 2012;1(3):276-284. doi: 10.1002/mbo3.30

37.Wang S, Zhang S, Liu Z, Liu P, Shi Z, Wei J, et al. Molecular characterization of enterohemorrhagic E. coli 0157 isolated from animal fecal and food samples in Eastern China. Scientific World J. 2014;2014:946394. doi: 10.1155/2014/946394.

38. Ananias M, Yano T. Serogroups and virulence genotypes of Escherichia coli isolated from patients with sepsis. Brazilian Journal of Medical and Biological Research. 2008;41(10):877-883.

39. Friedrich AW, Bielaszewska M, Zhang WL, Pulz M, Kuczius T, Ammon A, et al. Escherichia coli harbouring Shiga toxin 2 gene variants: frequency and association with clinical symptoms. J Infect Dis. 2002; 185(1): 74-84.

40. Dedeić-Ljubović A, Hukić M, Bekić D, Zvizdić A. Frequency and distribution of diarrhoeagenic Escherichia coli strains isolated from pediatric patients with diarrhoea in Bosnia and Herzegovina. Bosn J Basic Med Sci. 2009;9(2):148-155.

41. Kariuki S, Gilks C, Kimari J, Muyodi J, Getty B, Hart CA. Carriage of potentially pathogenic Escherichia coli in chickens. Avian Dis. 2002; 46(3):721-724.

42. Beutin L, Marches O, Bettelheim KA, Gleier K, Zimmerman S, Schmidt $\mathrm{H}$, et al. HEp-2 cell adherence, actin aggregation and intimin types of attaching and effacing Escherichia coli strains isolated from healthy infants in Germany and Australia. Infect. Immun. 2003;71(7):39954002. doi: 10.1128/IAI.71.7.3995-4002.2003

43. Vaishnavi $\mathrm{C}$ and Kaur $\mathrm{S}$. The epidemiological and resistrogram patters of enteropathogenic and enterotoxigenic Escherichia coli isolated from diarrhoeal stools in a North Indian hospital. Trop. Gastroent. 2003;24(2):70-72.

44.Garcia PG, Silva VL, Diniz CG. Occurrence and antimicrobial drug susceptibility patterns of commensal and diarrheagenic Escherichia coli in fecal microbiota from children with and without acute diarrhea. J Microbiol 2011;49(1):46-52. doi:10.1007/s12275-011-0172-8.

45. Kotloff K, Nataro JP, Blackwelder WC, Nasrin D, Farag TH, Panchalingam S, et al. Burden and aetiology of diarrhoeal disease in infants and young children in developing countries (the Global Enteric Multicenter Study, GEMS): a prospective, case-control study. Lancet 2013; 382(9888): 209-922. doi: 10.1016/S0140-6736(13)60844-2.

46. Bettelheim KA. The non-0157 shiga-toxigenic (verocytotoxigenic) Escherichia coli; under-rated pathogens. Crit Rev Microbiol. 2007;33(1): 67-87. doi: 10.1080/10408410601172172. 